\title{
The development of policy pertaining to potable water supply catchment areas in Victoria, Australia
}

\author{
A. C. Hurlimann \\ Lecturer in Urban Planning, \\ Faculty of Architecture Building and Planning, \\ The University of Melbourne, Australia
}

\begin{abstract}
This paper explores the development of policy pertaining to potable water supply catchment areas in the state of Victoria, Australia. A focus is placed on urban planning policy and development control. Historical research and policy analysis was undertaken to establish key influences on the development of this policy. The significant influences were found to include the establishment of water boards and authorities as referral authorities in planning schemes, the 'Sydney Water Crisis' of 1998, and the Gibson review of 'New Format Planning Schemes'. Existing policy is critiqued, and policy needs are highlighted. This paper will provide important lessons for other jurisdictions around the world regarding the protection of potable water catchments. Importantly, it will highlight the importance of development control to protect the quality and quantity of a city's water supply.
\end{abstract}

Keywords: catchment, watershed, management, urban planning, policy, water.

\section{Introduction}

The crisis of water management in many areas of Australia has heightened awareness of the importance of protecting water quality and quantity through effective catchment (watershed) management. Adequate control of land use and development through urban (urban and regional) planning policy is critical to support the aims of effective catchment management with regards to protecting water quality and quantity. It is acknowledged that there are many other 
components of catchment management including flora and fauna; however, the focus of this paper is the aspects regarding water quality and quantity. Given the current drought faced by many of Australia's major urban and rural areas, effective catchment management is an imperative. However, this is a sparsely researched or reported policy topic. The literature which does exist comes from diverse fields such as science, engineering, natural resource management and public policy. Additionally there have been recent calls for increased research, particularly into the resolution of the conflicts between urban development and rural landscapes [2,3]. Adding to the difficulty of implementation of good policy is the complexity of the governance contexts for water management at a local scale.

This paper explores the current policy context for potable water supply catchment areas in the State of Victoria, Australia. The state of Victoria is in the south east corner of the country. Most areas of the state have been facing an extended drought since the mid 1990s [4]. Historical research and policy analysis was undertaken to address this research imperative. The paper firstly outlines the importance of protecting water quality and quantity before describing the current planning policy context in Victoria. History regarding the development of this policy is then provided before key issues are highlighted and future research needs presented.

\subsection{The importance of protecting water quality}

The importance of ensuring a safe drinking water supply (protecting water quality) has been a concern for engineers and public health officials since the 1800s. This began with John Snow's discovery of a link between the contamination of water and communication of cholera. This gave rise to the closure (protection) of water catchments, as for Melbourne, Victoria's capital city. This importance has recently been highlighted by high profile outbreaks in potable water supplies of major cities such as Sydney, Australia in 1998. There were three major contamination episodes in Sydney between July 21 and September 19, 1998 which resulted in three boil water notices issued [5]. During this time the Sydney population were advised not to drink their tap water directly. Fortunately no increases in illness associated with water contamination were reported.

Hrudey and Hrudey [5] document 70 individual accounts of potable water supply outbreak case studies from 16 affluent nations from $1970-2000$. They estimate that there are thousands of additional outbreak cases, which are either unreported in literature, reported in a language other than English, or in nonaffluent nations. Some of the cases reported by Hrudey and Hrudey [5] ended tragically. To give just two examples, 7 people died at Walkerton Canada in the year 2000 and approximately 50 people died over a two year period in Milwaukee USA in 1993. In affluent nations, the public do not expect to die from drinking water from mains supply [5]. As such these incidents have drastic impacts on the communities involved. The importance of protecting potable water catchments from inappropriate development is well acknowledged by Hrudey and Hrudey [5, p.55]: 


\begin{abstract}
"Once human developments occur in a watershed (catchment) for either surface water or groundwater, the range and magnitude of water quality problems grow substantially along with the difficulty in successfully managing them. Development once allowed, cannot be easily reversed"
\end{abstract}

One outbreak case detailed by Hrudey and Hrudey [5] was that of Sunbury, Diggers Rest and Bulla, a suburban/rural region approximately $50 \mathrm{~km}$ north east of Melbourne. An outbreak of gastroenteritis occurred in October 1987 affecting an estimated 6,600 out of 19,000 residents. The water supply was found to be at substantial risk of contamination. There were no effective barriers in place to protect consumers, and this was found to contribute to the outbreak [5]. This case was an early warning for the Sydney crisis. Mr Bob Ford, former Manager of Catchment Policy for the Central Highlands Water Authority, said the case was a useful lesson for the Water Board he was associated with. It allowed the water officers to gaining support from the board for catchment protection.

A recognised key aspect of securing safe drinking water is a 'multiple barrier' approach to protection against contamination. A key component of a multiple barrier approach is source protection, usually put in practice through a watershed (source) protection program [6]. However such programs can be difficult to implement because of the multiple institutions that are necessarily involved. For example, in the case of Victoria, Australia it would be advantageous for the following institutions to take part in a catchment management protection policy: the water authority, the regional water authority, the catchment management authority, the local government authority, the state government, the community, developers, and other interest groups. Each of these institutions has a different role in the management of catchments. Such institutional complexity gives rise to the importance of integrated catchment management as advocated by Bellamy et al. [7] and Falkenmark et al. [8].

There is increasing pressure placed on many catchments in Victoria, Australia (and many other parts of the world). These pressures relate to increasing population, the need for affordable housing (and thus development of green wedges), and because of the increase in the 'sea change' and 'tree change' phenomena as described by Larsen [9] and Gibson et al. [2]. This has seen the movement of populations from major urban centres to coastal and rural communities. In rural areas this often puts pressure on land located in potable water catchments. The dangers present from the increased urban development in potable water catchments include increased pollution of water, particularly with regard to poor septic tank management. A code of practice for septic tank management exists in Victoria [10]. While this code details maintenance requirements, it is difficult for authorities to monitor compliance due to the number of septic tanks that exist and the area of land covered. Other inappropriate uses of land in potable water catchments are a concern, particularly livestock rearing and abattoirs [5]. Additional risks to safe drinking water include the increasing privatisation of water authorities. This has associated institutional implications (accountability), including increased focus on profit and thus reduction in maintenance and monitoring [5]. 


\subsection{The importance of protecting water quantity}

An important catchment management issue arising from the drought experienced by the state of Victoria is the protection of water quantity. The experience of some water authorities in drought affected areas, is that people are increasingly installing dams, illegally installing dams, or illegally increasing the size of existing dams. The weak control of bore and dam installation, and the institutional complexity, mean that overall management of water quantity in catchments is compromised. Anecdotal evidence suggests that an increase in small dams has compromised the central supply for particular regions (central dams controlled by the water authority for city and industry). These smaller dams fill up before the main dam supplying the region. Often these dams are for ornamental value and have high evaporation rates. The experience in managing the Mount Lofty ranges on the urban rural fringe of Adelaide (the capital city of South Australia) could potentially provide insight for other case studies. The Mount Lofty Ranges provide a large percentage of Adelaide city's water supply in an average rainfall year, and has been subject to proactive planning controls as described by Bunker and Houston [3].

\section{Planning policy context}

Adequate control of land use and development through urban and regional planning policy is critical to support the aims of effective catchment management with regard to protecting water quality and quantity. Thus, it is important to review current urban planning policy in Victoria. Urban and regional planning in Australia is of a discretionary nature, and the way in which development is controlled differs between the States. Development control in Victoria is primarily activated at the local level and is contained in each local government area's planning scheme. This control operates primarily through a system of zoning and overlay controls [11]. The Planning and Environment Act 1987 prescribes the matters which can be provided for in schemes, and the procedures for scheme amendments and administration [11]. Each municipality's planning scheme contains: a state planning policy framework (SPPF) (identical in all schemes), a local planning policy framework (LPPF) (varies for each municipality), zone and overlay provisions, particular provisions, general provisions, definitions and incorporated documents [12]. The Victorian planning system is a discretionary based planning system [11]. While the Planning and Environment Act 1987 and the Planning Schemes are the main vehicles for development control in Victoria, other mechanisms (policies, programs and legislation) do exist. The planning schemes of all Victorian municipalities can be found in full on-line [see: DPVC 13].

\subsection{Current policy context for potable water supply catchments in Victoria}

Table one outlines the current planning framework for Victoria, as relevant to catchment management. Key development control instruments are zones and 
overlays. An important distinction is that zones control land use and development, while overlays control development only. The distinction between zones with regards to purpose and minimal lot size is detailed. The zones are consistent in their description across the state. Each zone has a schedule attached to it, which differs between each local government area. The schedules define issues of a local concern such as minimum areas for which no permit is required for construction of a dwelling.

Importantly the zones detailed in Table one largely do not control farm dams. Some planning schemes do control dams through the Environmental Significance Overlay (ESO), for example Moorabool Shire. The Water Act 1989 sets the framework of the allocation of ground water and surface water across the state [for all Victorian Acts see: 14]. A construction and at times, use licence is required to be obtained from one of five 'licencing bodies' [15]. All groundwater bores in Victoria require a construction licence which ensures that the bore is constructed in accordance with requirements of the Water Act 1989. On completion of the construction of the bore, stock and domestic bores require no further licensing. All other bores require an extraction licence which is issued by the relevant Rural Water Authority [16].

\subsection{History of current catchment policy in Victoria}

A historical overview of the development of current catchment policy (aiming to protect potable water quality and quantity) in Victoria, is detailed below.

\subsubsection{Protection of potable water catchments in legislation}

In 1988 an amendment was made to the Public Health Act 1958. This amendment included minor changes to the existing Act and the introduction of new sections. This included the addition of a section (s. 81) titled 'Regulations for protecting water supplies'. This section outlined that the Governor in Council may make regulations for or with respect to eleven items, including; protecting water supply systems and catchments from contamination (a), directing water supply authorities to sample their water supply systems and requiring those samples to be tested by an approved laboratory for analysis (f), the inspection of water supply systems and catchments (k). In 2003 the Public Health Act 1958 was further amended. Section 81, and other water related sections were repealed by the Safe Drinking Water Act 2003. Thus potable water management is addressed in this purpose built Act. The act outlines the responsibilities of water suppliers to ensure that the drinking water they supply meets quality standards specified. Another important policy is the Australian Drinking Water Guidelines which are intended to provide a framework for good management of drinking water supplies to assure safety at point of use [17]. Chapter two of the guidelines deals with a framework for management of drinking water quality and includes a section on 'a preventive strategy from catchment to consumer'. 


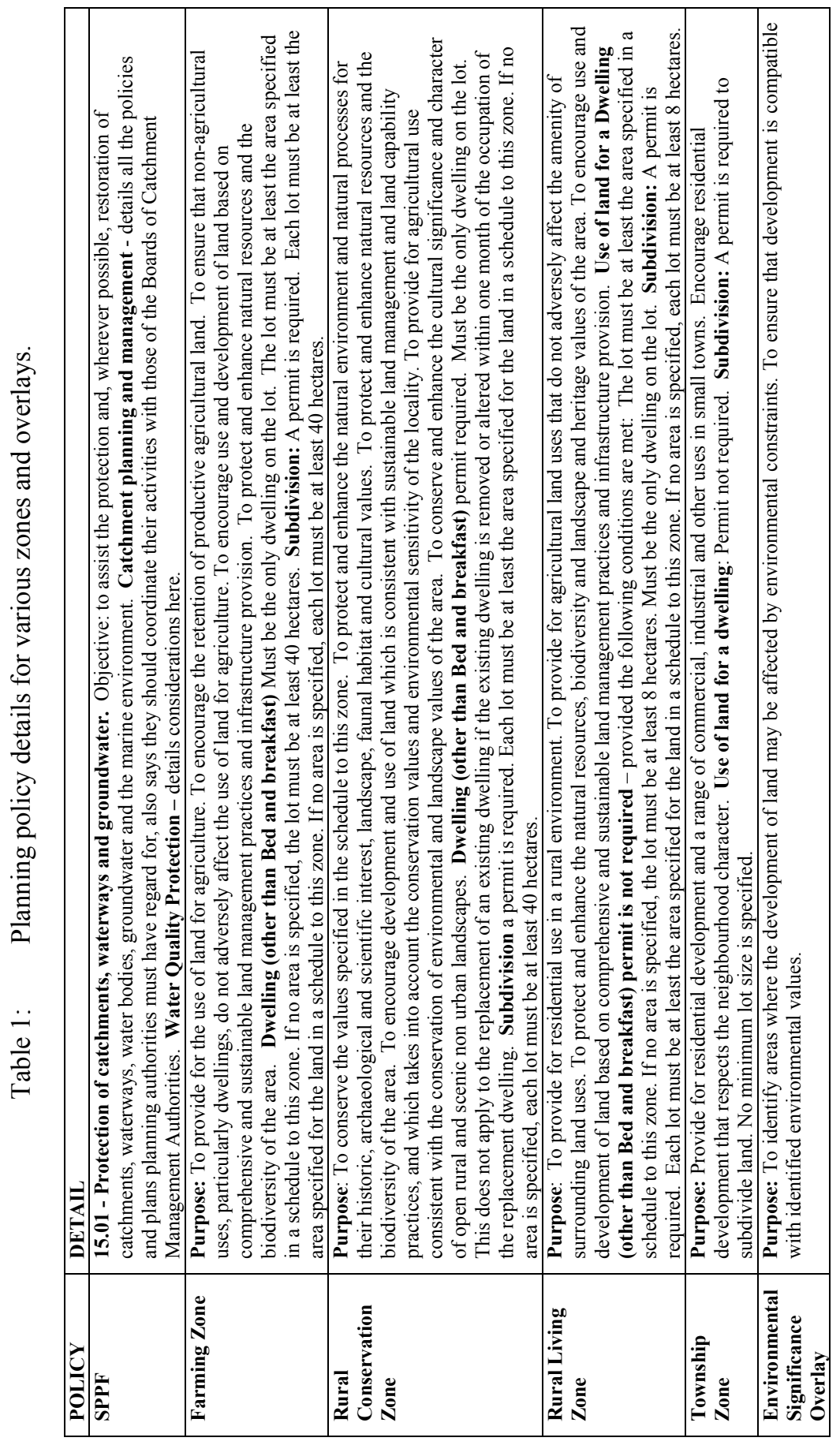




\subsubsection{The history of water authorities becoming referral authorities}

Another important aspect of development control with regards to catchment management in Victoria is the role of referrals under Section 55 of the Planning and Environment Act 1987. At Clause 66 of all Victorian Planning Schemes it is detailed that water boards and water supply authorities are referral authorities for proposals to: "use, subdivide or consolidate land, to construct a building or construct or carry out works, or to demolish a building or works that are within a Special Water Supply Catchment Area listed in Schedule 5 of the Catchment and Land Protection Act 1994", and which provides water to a domestic supply. Section 61(2) of the Planning and Environment Act 1987, states that a permit application must be refused if a referral authority objects to the granting of planning permit. Water Authorities became referral authorities on Wednesday 7 October 1992 after a ministerial amendment to all planning schemes in Victoria was approved [18]. Approval was given in the week preceding a State Government election, and subsequent notice was not printed until after the election (and subsequent change of Government).

Mr Bob Ford, former Manager of Catchment Policy for the Central Highlands Water Authority, believes that lobbying by various water authorities, and a number of planning appeal cases, influenced the approval of this amendment. The amendment was met with political pressures from local interest groups. It is thought the Minister's belief his party would loose the election was a contributing factor to the Amendment's approval at the eleventh hour.

\subsection{3 'New format planning schemes' and their review}

Important background information for the content of this paper is the history of the current planning policy context in Victoria. In 1992 a new (Liberal) government was elected to power in the State of Victoria (as mentioned above). This new government had a policy to create jobs and prosperity for the state through reformation of the planning system; by simplifying and clarifying the development approvals system; and improving their organisation [1]. As described by Gibson [1], shortly after the government was elected a committee was formed and given a mandate to produce recommendations on reform of various aspects of the state's planning system. As described by Gibson [1] the committee made a series of recommendations to the government with two key planning reform objectives: better planning schemes; and better approvals procedures. These objectives would be achieved by having: a policy basis for planning schemes and decision making; consistent statewide controls and provisions, with the ability for local discretion within an explicit policy context; and monitoring of system effectiveness. The reform aimed at achieving better processes through the introduction of better 'new format' planning schemes [1]. After introduction in November 1996, Councils were required to incorporate the new provisions into new format planning schemes by July 1997 [19]. An extension was given until December 1999 because of incompletion by some Councils [19]. 
Following their initial introduction there was a statewide review of the seventy nine 'new format' planning schemes. This involved teams of panel members travelling to each municipality to conduct hearings, consider submissions and review each exhibited new planning scheme in detail, and was then reported by Gibson [1] the chief panel member. This report was released one year after the Sydney water crisis. It appears this incident influenced the report's significant attention to issues of catchment management and to the report's recognition that "water will be the most valuable single resource of the new millennium". In total, the report made 34 recommendations regarding new format planning schemes, nine of which addressed issues of catchment management and the protection of water quality and quantity. The nine recommendations surrounded three key issues as discussed below.

Planning in rural areas: Gibson's [1] report highlighted that in rural areas, the greatest challenges facing planning in the new millennium, will be to: maintain agricultural land in productive use; ensure an ongoing supply of water for irrigation and stock purposes; and manage water supply catchments to ensure an adequate supply of high quality water for domestic consumption. Gibson [1] recognised the growth of residential use in agricultural zones and the conflicts this creates. The report also acknowledges that many people see the solution to the problems (including decreasing population and resources) of rural towns is increasing subdivision and hence population (which has impact on water quality and quantity). One of the report's recommendations related to the review and extension of the rural zones that existed at the time. This was undertaken, and has been in the process of being phased into planning schemes [20].

Protection of water quality: Gibson's [1] report recognises the importance of good catchment management for protecting the quantity of water resources, highlighting an issue is how this will be achieved. Gibson recognised the importance of catchment management in open potable water catchments where land users need to acknowledge the potential hazards of their activities and to accept that restrictions and conditions may be necessary for the overall benefit of the community. The Gibson report acknowledges that two key pollution sources in the Sydney incident were farming practices and septic tanks. Hrudey and Hrudey [5] state that a constructive lesson to emerge from the Sydney experience is the need to reduce the contamination of the raw water supply by focusing on better overall management of the watershed. One specific recommendation in the Gibson report involved the development of a model local law to deal with the ongoing maintenance of septic tanks. It appears the Environmental Protection Authority's [10] Septic Tank Code of Practice has addressed this recommendation, but not in the form of a local law.

Protection of water quantity: Gibson's [1] report stated it is possible that insufficient attention has been paid to the need for a permit for dams of any size diverting water from a permanent waterway. The report highlighted that managing the proliferation of farm dams associated with the growth in certain types of agriculture, such as viticulture, is a problem that requires immediate attention. One of the report's recommendations sought the introduction of a particular provision in Clause 52 of all schemes relating to dams, the 
requirements of which would include an assessment of the impact that construction of the dam would have on water flows and the amount of water available to downstream users. This recommendation had not been implemented when this paper was published.

Policy to protect catchments: Gibson's report recognised the limits of existing planning policy for protection of potable water supplies (zoning and overlays). The approach adopted in the Shire of Moorabool was recommended to be adopted elsewhere. This approach involves the use of the 'Environmental Rural Zone and an Environmental Significance Overlay' (ESO) over catchments. However it was acknowledged that there were still gaps in the level of control over significant potential sources of pollution. The ESO for potable water catchments only controls development and not use, allowing some inappropriate uses (such as intensive animal husbandry etc) to occur. Gibson recommended that a new overlay be established to apply to potable water catchments, one that would control both use and development. This recommendation had not been implemented when this paper was published.

The Gibson report also recommended that water authorities should develop a series of performance measures and conditions upon which certain use or development may proceed within water catchments without the need for referral to water authorities. While this did not explicitly occur, a 'Interim guideline for planning permit applications in open, potable water supply catchment areas' [21]. This guideline states it is applicable until a review of water catchment issues is completed. This review has not occurred. The guidelines have been challenged in many planning appeal cases. Recently the water authorities have lost cases at the Victorian Civil and Administrative Tribunal because the guideline has been challenged [22]. Water authorities have appealed three such decisions (thus taking them to the Supreme Court). To date, none have been heard. Numerous water authorities have expressed their desire for the guidelines to be made permanent by the Victorian Government, despite the review of water catchment issues not been undertaken.

\section{Conclusion}

This paper has provided a historical overview of the development of current urban planning policy for the protection of potable water catchments in the state of Victoria, Australia. This research has indicated that key influences to the current urban planning policy context for potable water catchments in Victoria have been: the establishment of water boards and authorities as referral authorities for development proposals in potable water supply catchments; the 'Sydney Water Crisis' of 1998; and the Gibson [1] review of 'New Format Planning Schemes'. While there have been improvements in policy with regards to potable water catchment management since 1988, further improvements are required, and some gains made since this time are under threat. Future urban planning needs include: 1) Actioning of Gibson's [1] recommendations regarding the protection of water quality and quantity; 2) Ensuring the Interim guideline for planning permit applications in open, potable water supply 
catchment areas' becomes a fully implemented guideline; 3) Further strengthening of the effective implementation of existing planning policy; and 4) Undertaking a water catchment issues study to strengthen urban planning policy dealing with catchment management. These needs must be addressed as a matter of urgency to ensure protection of water quality and quantity at this time of increasing uncertainty for supplies. The historical development of this policy in Victoria will provide useful insight for jurisdictions in other areas of the world.

\section{Acknowledgements}

The author would like to thank and acknowledge the following people and organisations for their assistance in making the production of this paper possible: Mr Bob Ford, former Manager of Catchment Policy for Central Highlands Water for his insight and guidance regarding catchment policy issues in the Central Highlands Water area and Victoria; Miss Julie Hayes for research assistance; and to the Faculty of Architecture Building and Planning at the University of Melbourne, for funding an Early Career Researcher Grant which enabled this research to occur.

\section{References}

[1] Gibson, H., Final Report: New Format Planning Schemes. 1999, Planning Panels Victoria: Melbourne.

[2] Gibson, C., R. Dufty, and D. Drozdzewski, Resident Attitudes to Farmland Protection Measures in the Northern Rivers Region, New South Wales. Australian Geographer, 2005. 36(3): p. 369-383.

[3] Bunker, R. and P. Houston, Prospects for the Rural-Urban Fringe in Australia: Observations from a Brief History of the Landscapes around Sydney and Adelaide. Australian Geographical Studies, 2003. 41(3): p. 303-323.

[4] Government of Victoria. Our Water Our Future. 2007. Online: http://www.ourwater.vic.gov.au/.

[5] Hrudey, S.E. and E.J. Hrudey, Safe Drinking Water: Lessons from Recent Outbreaks in Affluent Nations. 2006, London: IWA Publishing.

[6] Allen, M.J., J.L. Clancy, and E.W. Rice, The plain, hard truth about pathogen monitoring. Journal of the American water works association, 2000. 92(9): p. 64-76.

[7] Bellamy, J., et al., Integrated Catchment Management: Learning from the Australian Experience for the Murray-Darling Basin. 2002, CSIRO Sustainable Ecosystems: Canberra.

[8] Falkenmark, M., et al., Towards Integrated Catchment Management: Increasing the Dialogue between Scientists, Policy-makers and Stakeholders. Water Resources Development, 2004. 20(3): p. 297-309.

[9] Larsen, C., Time for a tree change. Business Review Weekly, 2007. 29(6): p. $18-22$. 
[10] Environment Protection Authority, Guidelines for Environmental Management - Septic Tanks Code of Practice. 2003, Victorian Environment Protection Authority: Melbourne.

[11] Eccles, D. and T. Bryant, Statutory Planning in Victoria. 3rd ed. 2006, Sydney: The Federation Press.

[12] Department of Sustainability and Environment, Planning: a short guide. 2005, Melbourne: Victorian Government.

[13] Department of Planning and Victorian Communities, Planning Schemes on Line. 2008. Online: http://www.dse.vic.gov.au/PlanningSchemes/

[14] Government of Victoria, Victorian Legislation and Parliamentary Documents. 2008, Victorian Government: Melbourne. Online: http://www.dms.dpc.vic.gov.au/

[15] Department of Sustainability and Environment, Your dam your responsibility: A guide to managing the safety of farm dams. 2007, Melbourne: Victorian Government. Online: http:/www.dse.vic.gov.au/CA256F310024B628/0/F629C733D187D6F0C A25735C0027B054/\$File/Your+Dam+Your+Responsibility.pdf

[16] Department of the Environment Water Heritage and the Arts, Water resources - Allocation and Use - Victoria, in Australian Natural Resources Atlas. 2007, Australian Government: Canberra. Online: http:/www.anra.gov.au/topics/water/allocation/vic/gmu-unincorporatedarea-otway-highlands.html

[17] National Health and Medical Research Council and Natural Resource Management Ministerial Council, Australian Drinking Water Guidelines 6. National Water Quality Management Strategy. 2004, Canberra: Australian Government.

[18] Victorian Government Gazette, Notice of Approval of Amendment, Amendment S9, in No. G39, Wednesday 7th October. 1992, Government Printer Melbourne: Melbourne.

[19] Buxton, M., R. Goodman, and T. Budge, A Failed Experiment: The performance of the Victorian Planning Provisions and the new format planning schemes. 2003, Melbourne: RMIT University.

[20] Department of Sustainability and Environment, New Zones for Rural Victoria. Advisory Note. 2004, Melbourne: State Government of Victoria.

[21] Department of Infrastructure, Interim guideline for planning permit applications in open, potable water supply catchment areas. 2000, Victorian Government: Melbourne.

[22] Barber, P., K. Piskuric, and P. O'Farrell, Residential development in potable water catchments. Planning News, 2008. 34(1): p. 24. 